The Brock Review Volume 11 No. 2 (2011)

(C) Brock University

\title{
Communicative Lands, Community Landscapes
}

Katharine T. von Stackelberg

"Place incarnates the experiences and aspirations of a people."1

The world's oldest urban community is the Neolithic settlement discovered at Çatalhöyük in Anatolia, modern Turkey. In one of the larger structures, provisionally identified as a shrine, is the site of the earliest landscape painting, depicting the houses of Çatalhöyük under the double volcano of Hasan Dağ, the source of the community's obsidian economy and possibly a seat of divine power.

Who would have seen the painting? Occupants of the house alone? The community as a whole? Ritual inductees? Visiting travelers and traders? The exact audience for the Çatalhöyük landscape cannot be determined, but the primacy of the visual in a pre-literate culture demands that the viewer pay attention. Nine millennia ago a human community perceived their environment as something special, selected its elements and re-presented them in a nine-foot mural. This artifact marks the start of a conceptual process whereby landscape is differentiated from nature as a response to the emergence of urban communities. Çatalhöyük's landscape "map" indicates that is not enough simply to occupy a space, we need to reflexively mark that occupation, defining and negotiating personal, political and economic boundaries: making space into place is an act of communication.

Communicative Lands: Community Landscapes emerged as the theme of this issue of The Brock Review following the Greenscapes conference Fields of Dreams: Landscapes of Myth and Imagination held at Brock University in October 2009. This interdisciplinary conference explored the perception and phenomenology of landscapes as communicative devices. The papers selected for this issue present a variety of ways in which landscape functions as an active matrix for expressions of social concern. Two interconnected themes emerge: the representation of landscape as an expression or subversion of colonial discourse, and as a part of a memorializing aesthetic that directs patterns of community engagement. 
Jakub Zdebik prepares the ground for both themes by offering a phenomenological approach to the landscapes of Robert Smithson and Paterson Ewen through Deleuzian strata and Kant's geographical metaphors. The abstract thought processes that eddy through our conscious and unconscious minds find material expression in works such as Island Project (Smithson 1970) and Rocks Moving in the Current of a Stream (Ewen 1971). For both artist and philosopher the organizational functions of geology/topology can articulate expressions of other complex organic systems, including social systems. This point is further developed by Johannes Zechner's account of the ideological creation of the German forest in response to emerging national ideation of the nineteenth century. Here a consensual communal fiction concerning German identity co-opted both landscape and ecosystem in an act of retro-colonisation (a specious reclamation of pre-Roman Germania), that not only anthropocentrised but Teutonised the forest.

This dark side of landscape and community (Volksgemeinshaft) manifests in its organizational basis. Native and alien are the categories of both ecological conservation and ethnic cleansing. In Derritt Mason's paper these categories are extended to articulations of homo- and hetero-sexual identity in the hypermasculine topography of Wyoming. Mason explores the paradox of a landscape presented in Ang Lee's adaptation of Annie Proulx's Brokeback Mountain that simultaneously encourages and punishes sexual individualism. The badlands' outlaw mythos presents a social topography that claims to resist the cultural judgments of others, but the isolation of the landscape translates to exposure when the colonizing narrative of the West is subverted by queer identity.

Identity is also at the heart of the memorializing aesthetic of landscape. Nadine Brundrett traces how the phenomenon of Roman tomb gardens directed patterns of community memory and engagement. Tombs were the locus of personal acts of commemoration, but also communicative vectors due to their disposition in necropoli along the main roads leading into urban settlements. Gardens attached to tombs not only referenced the cultural desideratum of stable land stewardship, their productivity reinforced social commensality through on-site feasts that commemorated the dead. What we perceive as lonely, abandoned areas were active spaces within the Roman social matrix. Even when these sites were eliminated by private development (as with the Horti Maecenatis) they continued to be part of the mental topography of their community.

Transitional landscapes connecting the communities of the living and the dead are found again in Chicago's Cabrini Green. Nicola Mann's account of the impending demolition of this public 
housing complex describes a landscape of usable memory: social clubs, corner stores and beauty parlours that stand in opposition to the dominant municipal representation of necrotic housing and environmental failure. Mann's analysis of these rhizomatic community interconnections as expressed through the work of Daniel Roth and Kerry James Marshall traces an ecology of personal relationships established over time. Roth's Cabrini Green Forest (2004) articulates the socio-ecological trauma felt by residents excluded from the current urban renewal initiative while Marshall's Garden Project (1994-7) challenges the viewer to reassess the grim reputation of these 'failed environments'. The urban landscape shapes and preserves community memory, and is therefore as worthy of preservation as the 'natural' landscape.

This sentiment would have been unpalatable and incomprehensible to William Morris, the subject of Elysia French's article on the ideology, ethics and aesthetics of environment. Morris abhorred industrial urbanism, considering it to be both an expression of and a motivating force behind social inequality. The pollution of the River Thames by industrial and human waste transmitted disease to the poorest sections of society in nineteenth-century London. French explores Morris' advocacy of water purity as the index of environmental health in his novels and his expression of these ideals in the lush meanders of his textiles and wallcoverings. Can fabric swatches influence social policy? If so, the implications for Timorous Beasties' Glasgow Toile are staggering.

Rivers, urban topography and community memory are the subject of John Peterson's pedagogical report about a student visit to the Los Angeles River. The river has had a role in shaping perceptions of the city from Juan Crespi's description of the settlement to Terminator 2: Judgement Day. Cities and water are intrinsically connected (although at this point the philologist in me feels compelled to alert the reader that the reiteration of James Hillman's claim that polis, the Greek word for city, originates in "a pool of meanings related to water" is a false etymology). The river's transformation from seasonal dry-bed to paradisical channel of California boosterism, and its subsequent relegation from natural resource to concrete flood control channel provides a case study for an "Urban Nature Writing" class. Student responses trace their realization that they are never outside nature, even when nature doesn't look like what they expect. And it is that unexpectedness that is the ultimate message of our landscapes. 
With thanks to the members of the Humanities Research Institute and Social Sciences and Humanities Research Council for their funding and support.

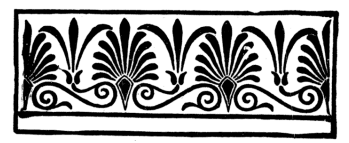

\section{Notes}

${ }^{1}$ Yi-Fu Tuan, Space and Place: The Perspectives of Experience, 1974: 213. 